\title{
14
}

\section{Techniques to Avoid and Decode Weird Looking Flow Monitoring Data}

\author{
Joseph S. Pang
}

Collection system flow monitoring programs have become key components in the asset management programs of many local utilities. These programs provide not only information about the volume, peak and temporal variation of flow conveyed in collection systems under various hydrologic and hydraulic conditions, but also valuable information to engineers about the performance and capacity of their systems. However, the effectiveness of these programs in providing this information depends on collecting accurate flow monitoring data from the systems, which is often not easy to do for various site specific and hydraulic reasons.

As a result, the processes used for selecting appropriate flow monitoring locations and the methods used for analyzing the resulting data are very important. If flow monitoring locations are not selected appropriately or if the collected data are not analyzed systematically, there may be unwanted effects on impact flow volume, peak quantification and numerical model calibration efforts that utilize them. This may lead to the generation of erroneous results and render any resulting engineering effort futile.

For collection system monitoring, a common type of monitoring technology is area-velocity $(\mathrm{A} / \mathrm{V})$ meter. An $\mathrm{A} / \mathrm{V}$ meter collects depth and velocity time series of flow at a monitoring location. These time series are used for generating flow time series for the monitoring location. This chapter describes procedures for selecting flow monitoring locations and analyzing flow monitoring time series obtained from this type of meter.

Pang, J. 2012. "Techniques to Avoid and Decode Weird Looking Flow Monitoring Data." Journal of Water Management Modeling R245-14. doi: 10.14796/JWMM.R245-14.

(C) CHI 2012 www.chijournal.org ISSN: 2292-6062 (Formerly in On Modeling Urban Water Systems. ISBN: 978-0-9808853-7-8) 


\subsection{Fundamental Concepts}

The flow monitoring location selection and data analysis procedures for $\mathrm{A} / \mathrm{V}$ meters described in this chapter utilize five fundamental hydraulic concepts. These concepts, which are described in the following sections, are:

mean velocity profile;

Manning's flow;

Froude number;

water surface profile in gradually varied flow; and

temporal synchronization of depth and velocity time series.

\subsubsection{Mean Velocity Profile}

Due to the effect of shear stress, the velocity of fluid particles in flow varies with their relative distance from the wall of the conduit in which they flow. This results in the formation of a velocity profile between any point in the flow and the walls of the conduit. For open channel flow, the velocity of fluid particles varies from zero (assuming a no-slip condition) immediately adjacent to the wall of the conduit to some velocity at the fluid-air interface. Figure 14.1 illustrates the velocity profile developed in open channel flow.

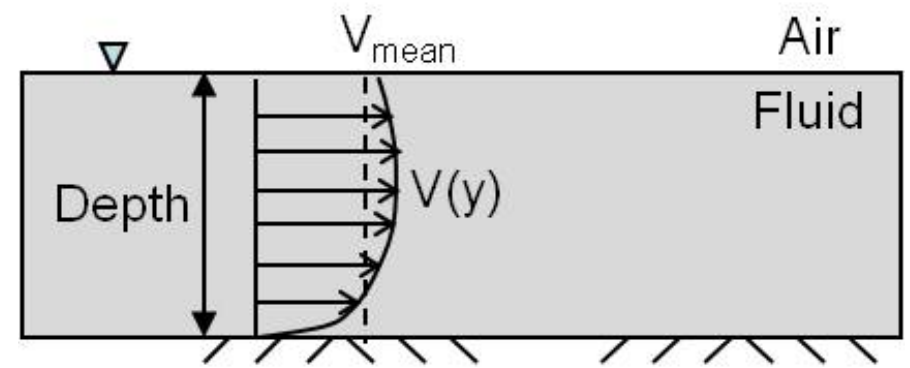

Figure 14.1 Open channel flow velocity profile.

From the velocity profile, the mean longitudinal velocity of flow across the whole depth can be calculated using Equation 14.1. Mean longitudinal velocity will be referred to as mean velocity in the following.

$$
V_{\text {mean }}=\frac{\int_{0}^{\text {Depth }} V(y) d y}{\text { Depth }}
$$

where:

Depth = depth of flow, 


$$
\begin{aligned}
V_{\text {mean }} & =\text { mean velocity across depth of flow, and } \\
V(y) & =\text { longitudinal velocity of fluid at depth }(\mathrm{y}) .
\end{aligned}
$$

In essence, mean velocity is the average of the velocity profile developed across the whole depth of flow as illustrated on Figure 14.1.

In many open channel flow applications, mean velocity across the depth of flow, $V_{\text {mean }}$, rather than the velocity of fluid particles at any particular depth, $V(y)$, is used in analyses. Rather than using the integral shown in Equation 14.1, one can directly calculate the mean velocity of flow by using the Manning's equation as shown in Equation 14.2.

$$
V_{\text {mean }}=\frac{1.49}{n} R_{h}^{\frac{2}{3}} S^{\frac{1}{2}}
$$

where:

$$
\begin{aligned}
n & =\text { Manning's roughness coefficient, } \\
R_{h} & =\text { hydraulic radius, and } \\
S & =\text { friction slope. }
\end{aligned}
$$

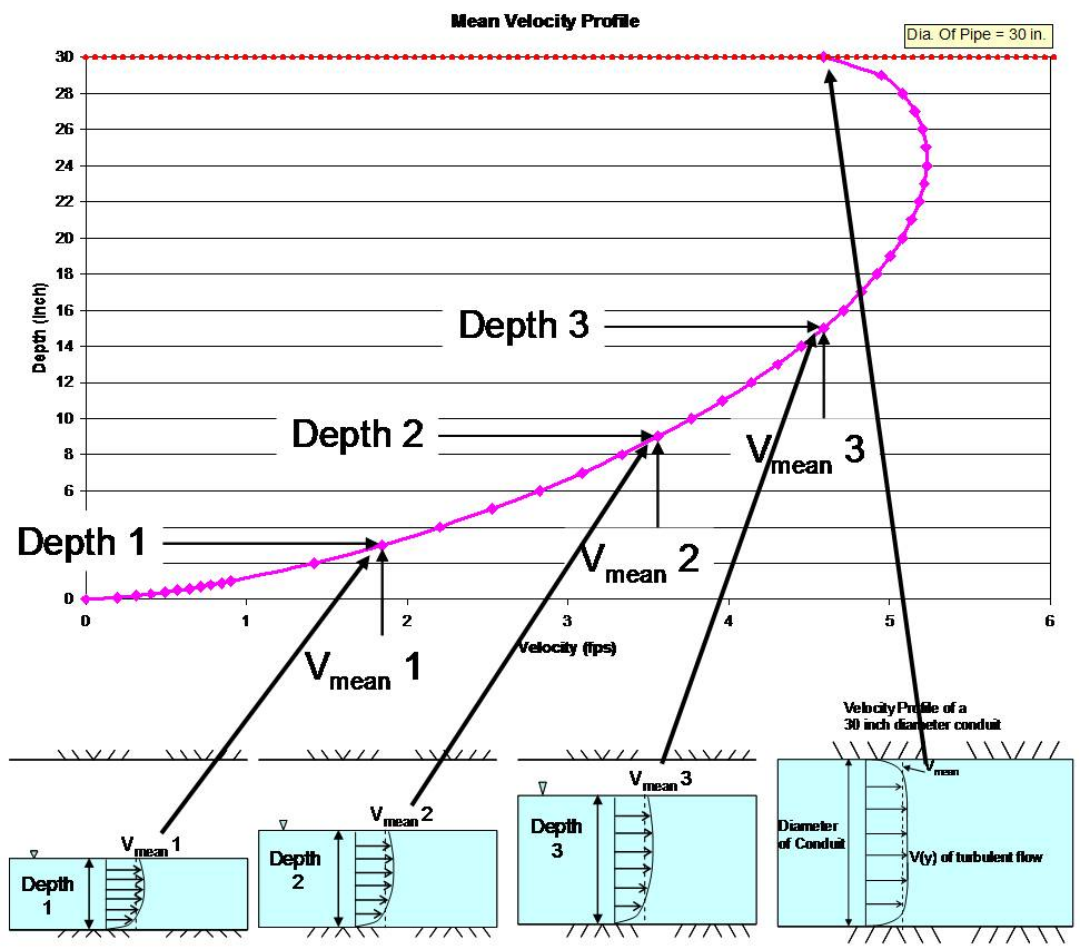

Figure 14.2 Mean velocity profile plot for a 30 in. circular conduit. 
The concept of mean velocity profile is to calculate the mean velocities of various depths of flow in a conduit and plot them against depth onto a graph with velocity in the $\mathrm{x}$-axis and depth in the $\mathrm{y}$-axis. Figure 14.2 above shows an example of such a graph and it will be referred to as a mean velocity profile plot hereinafter.

It should be noted that although the mean velocity profile looks very similar in shape to the velocity profile of flow, the two should not be confused. These two types of profiles are different and are not interchangeable. Their differences are especially pronounced in a full conduit. Figure 14.3 illustrates their difference. The procedures presented here utilize mean velocity profile rather than velocity profile of flow.

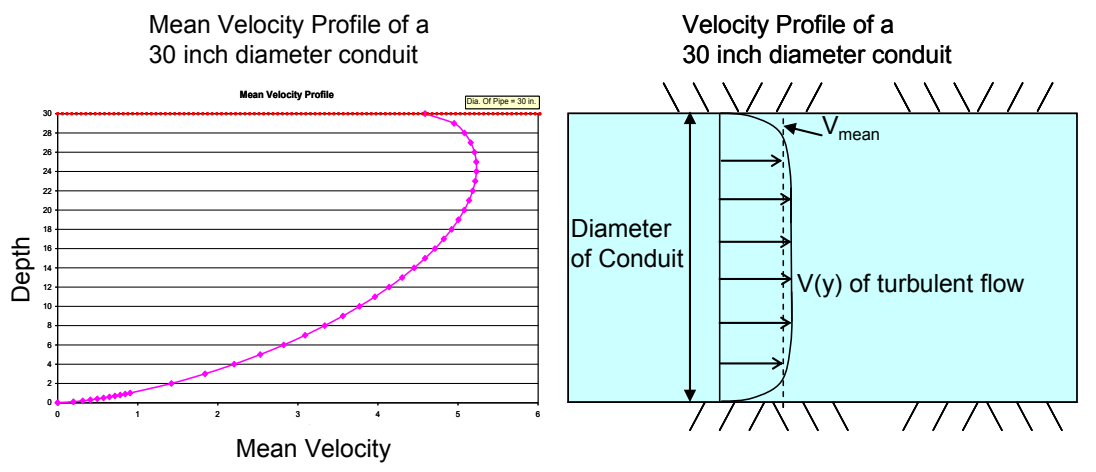

Figure 14.3 Difference between mean velocity profile and velocity profile.

\subsubsection{Manning's Flow}

After calculating the mean velocity distribution across various depths of flow, one can calculate the quantity of flow at each depth by multiplying the crosssectional area of flow at each depth by the corresponding mean velocity by using Equation 14.3.

$$
Q=V_{\text {mean }} * A
$$

where:

$$
\begin{aligned}
Q & =\text { flow } \\
V_{\text {mean }} & =\text { mean velocity, and } \\
A & =\text { cross-sectional area of flow. }
\end{aligned}
$$

When $V_{\text {mean }}$ is used as velocity, the flow calculated is the Manning's flow of the conduit. One can create a plot of the distribution of Manning's flow across depth by plotting Manning's flow on the $\mathrm{x}$-axis and depth of flow on the $\mathrm{y}-$ 
axis. Figure 14.4 shows an example of such graph. The curve on the graph will be referred as Manning's flow curve and the whole graph will be referred as Manning's flow plot.

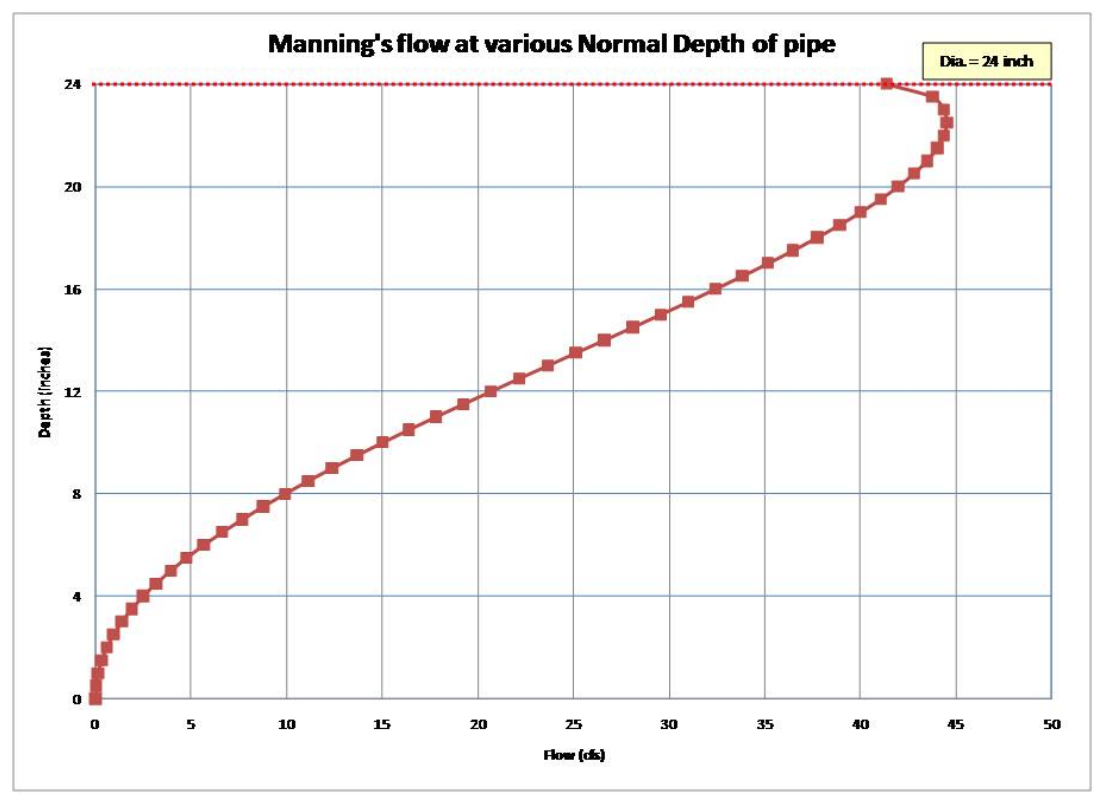

Figure 14.4 Manning's flow curve.

\subsubsection{Froude Number}

Generally, open channel flow in a conduit can be classified into three types of flow regime: subcritical, critical and supercritical. Each of these regimes is associated with their range of Froude number $\mathrm{Fr}$ which can be calculated by using the following equation.

$$
F r=\frac{V_{\text {mean }}}{\sqrt{g D_{h}}}
$$

where:

$$
\begin{aligned}
F r & =\text { Froude number } \\
\sqrt{ } g D_{h} & =C, \text { celerity of shallow water wave in a conduit, } \\
g & =\text { gravitational constant, and } \\
D_{h} & =\text { hydraulic depth of flow, which is defined as (Daugh- } \\
& \text { erty, 1985): }
\end{aligned}
$$




$$
D_{h}=\frac{A}{B}
$$

where:

$$
\begin{aligned}
& A=\text { cross-sectional area of flow }, \text { and } \\
& B=\text { width of flow area at the water surface. }
\end{aligned}
$$

The Froude number is a dimensionless number for flow in which inertia and gravitational forces are dominant. These two types of forces are the primary dominant forces in open channel flow. The characteristic Froude number for each of the aforesaid flow regimes is as follows:

- subcritical flow: $F r<1$;

- critical flow: $F r=1$; and

- supercritical flow: $F r>1$.

By plotting $V_{\text {mean }}$ of flow at various depths on the y-axis and the corresponding celerity $C$ on the $\mathrm{x}$-axis of a graph, the Froude number of the flow at various depths can be represented graphically. The units of velocity, depth and gravitational constant used to generate such graph are not relevant as long as they are consistent, as the Froude number is dimensionless. Figure 14.5 shows an example of such a graph. Such a graph will be referred to as a Froude number plot.

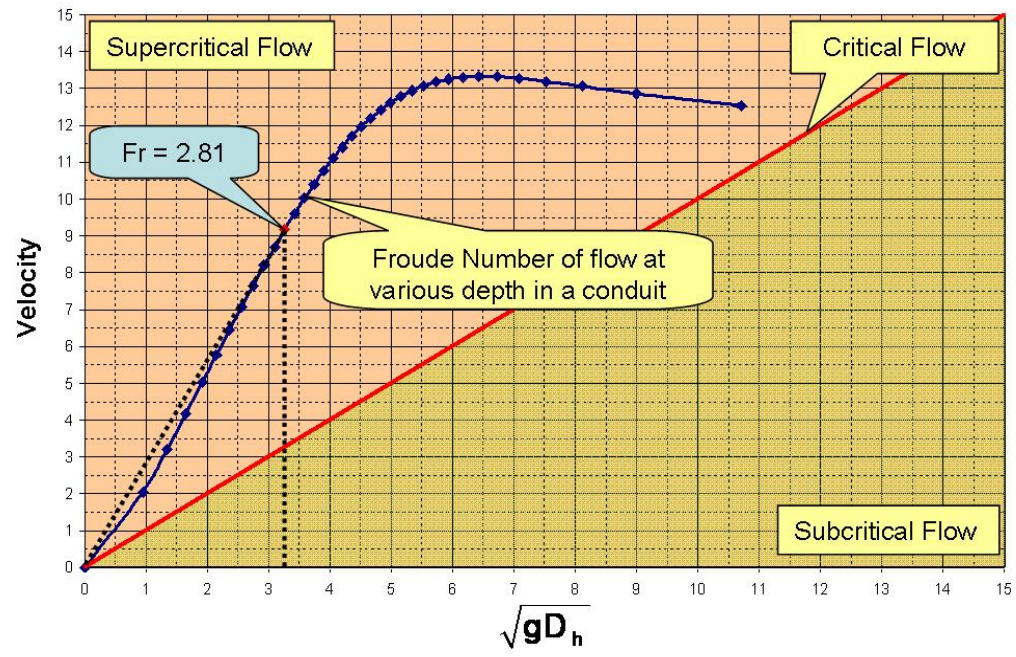

Figure 14.5 Froude number plot. 
The Froude number plot is configured specifically in the following way. First, the vertical and horizontal axes both start at the origin $(0,0)$ and end at the same maximum value such that a $45^{\circ}$ diagonal line can be drawn across the plot. The establishment of such a $45^{\circ}$ diagonal line is essential as the ratio of $V_{\text {mean }}$ and $C$ along this line is 1 . This line represents critical flow $(F r=1)$ and it establishes the boundary between subcritical and supercritical regions of the plot. It is shown as a $45^{\circ}$ diagonal line on Figure 14.5 and it will be referred as the critical flow line hereinafter.

Second, the region of the plot below the critical flow line represents ratios of $V_{\text {mean }}$ and $C$ less than 1 which translates to $F r<1$ and subcritical flow.

Third, the region above the critical flow line represents ratios of $V_{\text {mean }}$ and $C$ greater than 1 which translates to $F r>1$ and supercritical flow.

Fourth, the diamonds line on the plot is conduit specific and it is generated by plotting $V_{\text {mean }}$ and $C$ at various depths of flow in a conduit. It will be referred to as the Froude number curve of a conduit hereinafter. The slope of a line between a point on the Froude number curve and the origin $(0,0)$ of the plot represents the Froude number of that point. For example, a Froude number of 2.81 on the Froude number curve is represented by the ratio of $V_{\text {mean }}=9.3$ and $C=3.3$. If the Froude number curve falls below the critical flow line, the regime of flow in the conduit is subcritical. If the Froude number curve falls above the critical flow line, the regime of flow in the conduit is supercritical. If the Froude number curve falls on the critical flow line, the flow is critical.

Finally, the maximum Froude number of a conduit is represented by the inflection point of the Froude number curve which has the minimum curvature within the more linear portion of the curve. For example, the maximum Froude number of the Froude number curve shown on Figure 14.5 is 2.81. The maximum Froude number gives an indication of the magnitude of the flow regime that the flow experiences. It is also a representative indicator of the general flow regime of the flow in a conduit.

\subsubsection{Water Surface Profile in Gradually Varied Flow}

There are five kinds of water surface profile transitions in open channel flow. Each kind is described by its individual group of curves. Table 14.1 lists each kind of transition and their corresponding group of curves along with the relative position of depth of flow $y$ in relation to normal depth $y_{n}$ and critical depth $y_{c}$ in a conduit. Familiarity with the shapes of these curves and their positions in relation to $y_{n}$ and $y_{c}$ for each of the flow regimes is essential to using the procedures discussed in this chapter. Figure 14.6 shows the shapes of each of these curves. 
Table 14.1 Five kinds of water surface profile transitions.
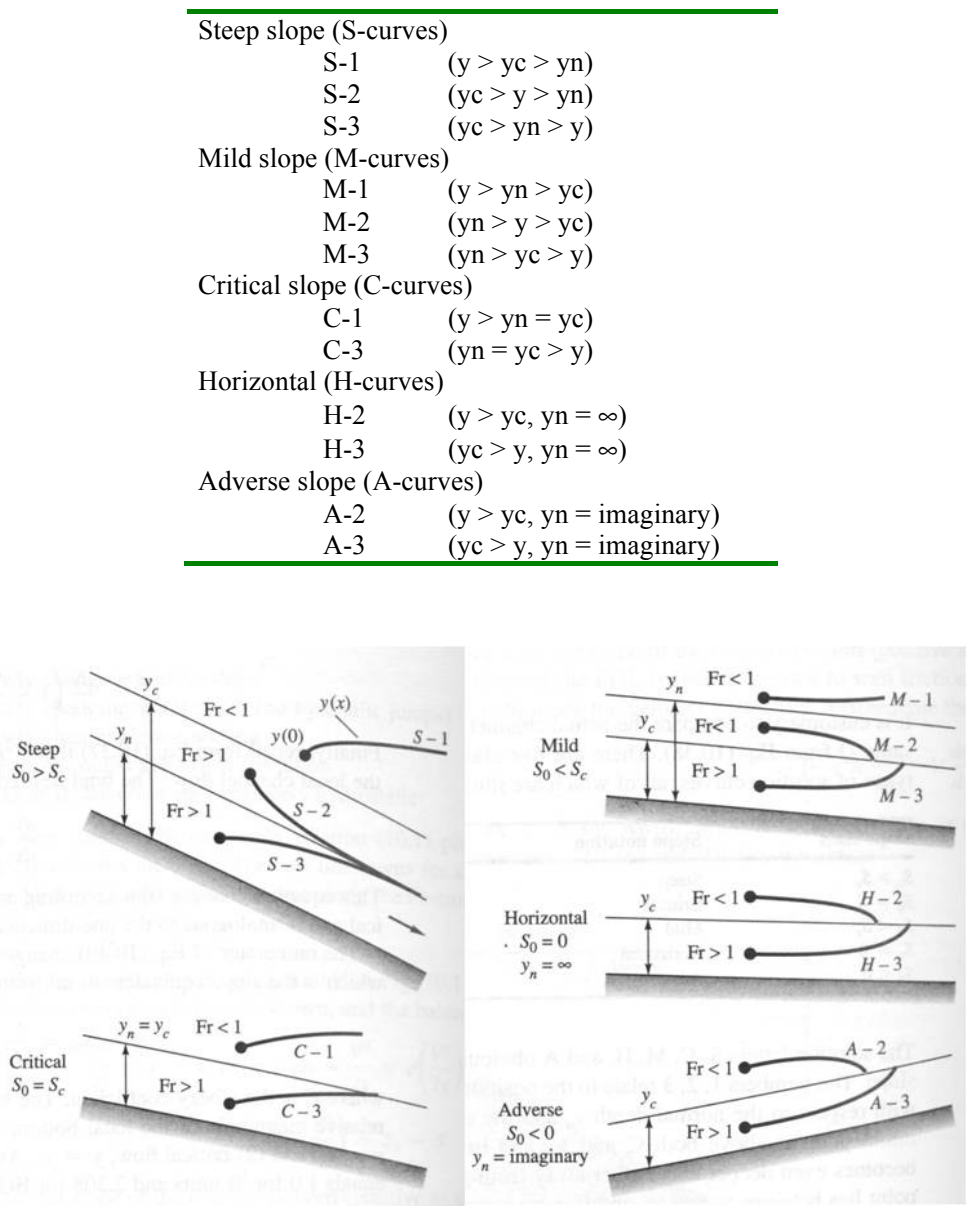

Figure 14.6 Kinds of water surface profile transition (White, 1994).

\subsubsection{Temporal Synchronization of Depth and Velocity Time Series}

In open channel flow, velocity and depth are functions of each other. As a result, unless there are other external forces acting on the flow besides inertia and gravity (e.g. flow is affected by controls), both depth and velocity time series should trend together in terms of how they change. Figure 14.7 shows an example plot of a depth time series and a velocity time series that trend together. Figure 14.8 shows an example of a depth and velocity time series plot which shows drifting of the velocity sensor. 


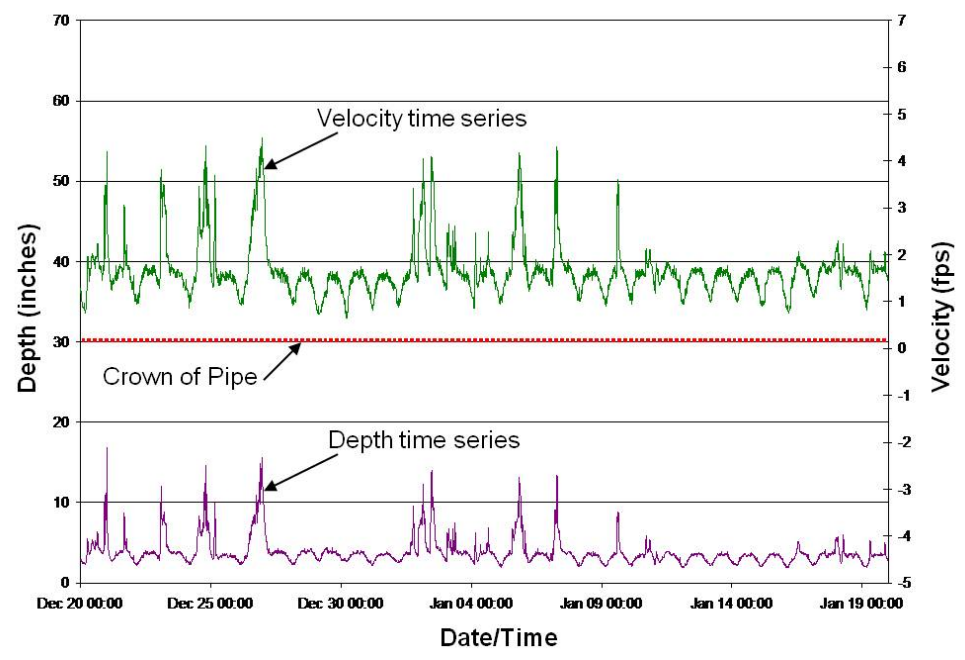

Figure 14.7 Temporal synchronization of depth and velocity time series.

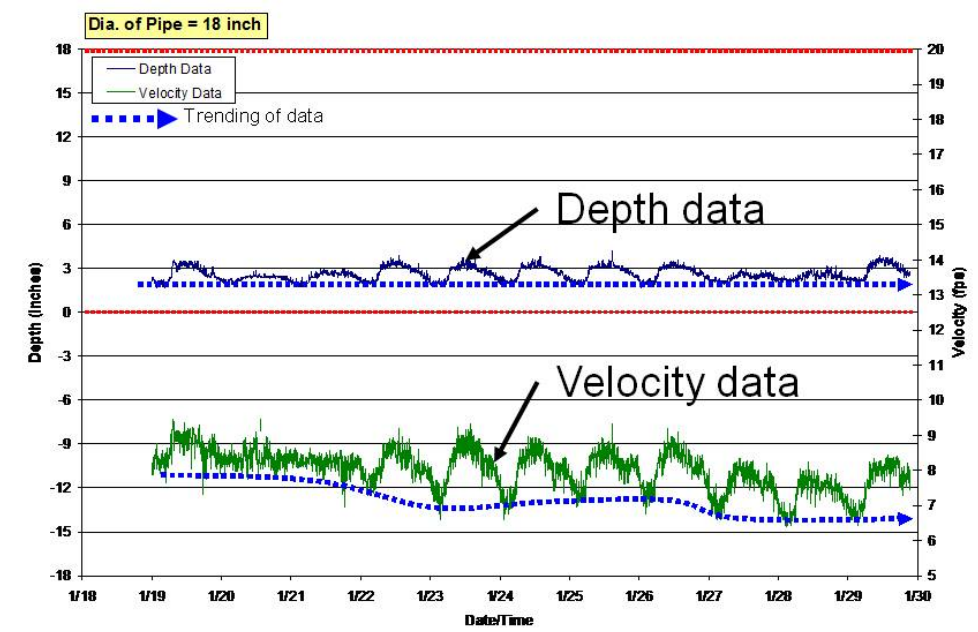

Figure 14.8 Drifting of velocity sensor.

Such a plot of depth and velocity time series provides some information that the other aforementioned concepts and plots cannot provide. It can tell us whether there are any mechanical issues with the measuring equipment (e.g. drifting of depth or velocity sensors) or whether the flow is controlled. The set 
of depth and velocity data shown on Figure 14.8 should trend together like those shown on Figure 14.7. However, the velocity data changes when the depth data does not.

This plot can be created by plotting depth and velocity onto the vertical axes with both series plotted one on top of the other against the same horizontal time axis as shown on Figures 14.7 and 14.8. Plotting the time series this way provides a clear way to see the trending of both time series against time.

\subsection{Applications}

The concepts discussed above can be used for selecting flow monitoring locations and analyzing flow monitoring data. The following sections describe how they are used in each of these applications.

\subsubsection{Selection of Flow Monitoring Location}

Initially selecting flow monitoring locations correctly can help to minimize the chances of collecting weird looking flow monitoring data. For the selection of flow monitoring location, the concepts of Froude number, Manning's flow and water surface profile in gradually varied flow are used. The procedures for using these three concepts for the selection of flow monitoring locations are as follows.

\section{Application of Froude Number}

After an engineer has identified potential section(s) of sewers into which they want to install flow monitors based upon other factors, such as the geography of a monitored area or the layout of a sewer system, they should produce a Froude number plot for each section of sewer according to the procedure described in section 14.1.3 above. After the plots are produced, they provide information about the flow regime (i.e. subcritical, critical or supercritical) in each section of sewer. Information about the flow regime in each section of sewer is essential for determining the water surface profile of gradually varied flow along sections of connected sewers and the locations of hydraulic phenomena such as hydraulic jumps.

\section{Application of Manning's Flow and Water Surface Profile in Gradually Varied Flow}

After the engineer has created a Froude number plot for each of the sewer sections, they should create a Manning's flow curve for each of the sewers and plot them onto the same graph. The purpose of plotting these curves together is to identify how the water surface profile changes from one conduit to another 
for various flow quantities. Thus the curves that are plotted together should be from sewers that are connected together. Figure 14.9 shows an example of one such graph.

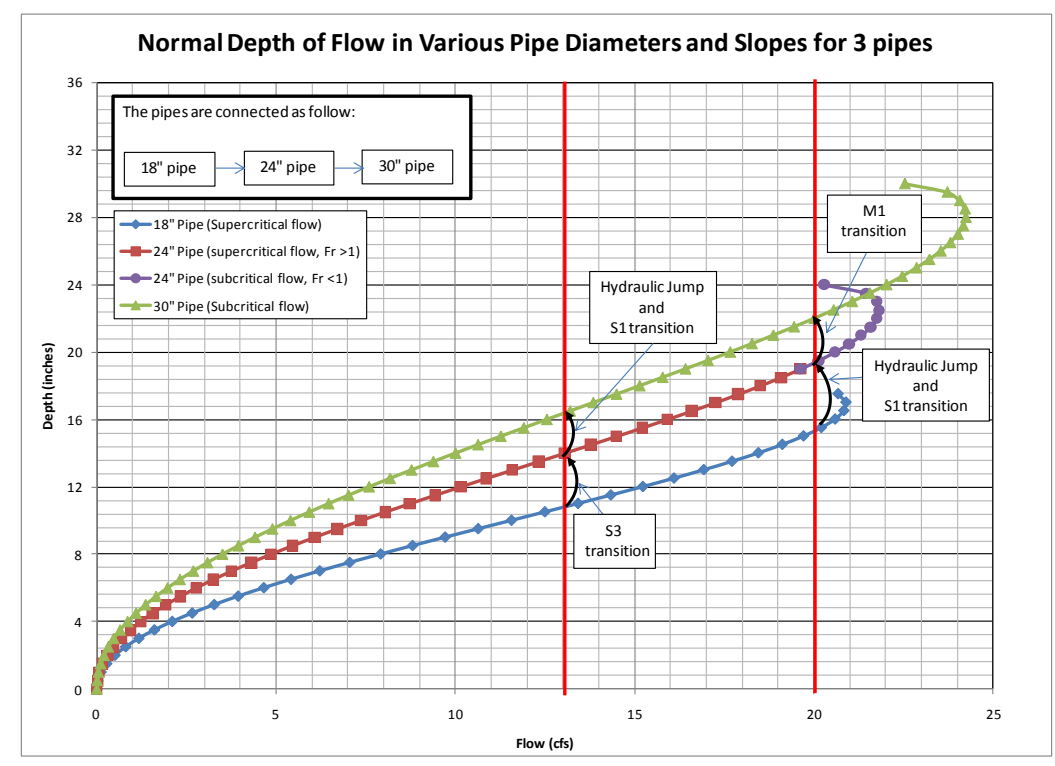

Figure 14.9 Manning's flow curves of connected pipes.

For the example shown on Figure 14.9, one can readily identify how water surface profile changes from one conduit to another. The lower (diamonds) curve is for an $18 \mathrm{in}$. $(457 \mathrm{~mm})$ pipe and it is connected to a $24 \mathrm{in}$. $(610 \mathrm{~mm})$ pipe which is represented by the middle (squares) curve. The $24 \mathrm{in} .(610 \mathrm{~mm})$ pipe is then connected to a $30 \mathrm{in}$. $(762 \mathrm{~mm})$ pipe represented by the upper (triangles) curve. From the Froude number plots that have been created for these three pipes, it is known that flow in the $18 \mathrm{in} .(457 \mathrm{~mm})$ pipe is subcritical $(F r<1)$, flow in the $24 \mathrm{in}$. $(610 \mathrm{~mm})$ pipe is supercritical $(F r>1)$ up to $19.5 \mathrm{in}$. (495 mm) depth, and then becomes subcritical $(F r<1)$ when the depth of flow is greater than $19.5 \mathrm{in}$. (495 mm). The flow in the $30 \mathrm{in}$. $(762 \mathrm{~mm})$ pipe is subcritical $(F r<1)$.

To illustrate how the graph on Figure 14.9 can be used to identify water surface profile transition, let us look at a scenario when flow is $13 \mathrm{ft}^{3} / \mathrm{s}$ $(368 \mathrm{~L} / \mathrm{s})$. At this flow rate, depth of flow increases as flow goes from the $18 \mathrm{in}$. $(457 \mathrm{~mm})$ pipe to the $24 \mathrm{in}$. $(610 \mathrm{~mm})$ pipe. As both pipes are in a supercritical flow regime $\left(\mathrm{y}_{\mathrm{c}}>\mathrm{y}_{\mathrm{n}}\right)$, section 14.1.4 above shows that the flow will have to go through an S-3 curve transition as that is the only way that flow can increase in 
depth while staying in the supercritical flow regime. When flow reaches the 30 in. $(762 \mathrm{~mm})$ pipe, flow depth increases further. As flow in the $30 \mathrm{in.}(762 \mathrm{~mm})$ pipe can only be subcritical, section 14.1.4 above shows that the flow will have to go through a hydraulic jump and an S-1 curve transition, as that is the only way that flow depth can increase and change the flow regime from supercritical to subcritical.

When flow in the three pipes is increased to $20 \mathrm{ft}^{3} / \mathrm{s}(566 \mathrm{~L} / \mathrm{s})$, the flow regime of the 24 in. $(610 \mathrm{~mm})$ pipe has become subcritical. As a result, when flow from the 18 in. $(457 \mathrm{~mm})$ pipe reaches the 24 in. $(610 \mathrm{~mm})$ pipe, the flow will have to go through a hydraulic jump and an S-1 curve transition. When the flow reaches the $30 \mathrm{in}$. (762 mm) pipe, the flow will go through an M-1 curve transition as both the 24 in. $(610 \mathrm{~mm})$ and $30 \mathrm{in} .(762 \mathrm{~mm})$ pipes are in subcritical flow and M-1 transition is the only way flow at normal depth can increase in depth in subcritical flow regime. Figure 14.10 shows what the surface profile looks like when flow in the three pipes is $20 \mathrm{ft}^{3} / \mathrm{s}(566 \mathrm{~L} / \mathrm{s})$.

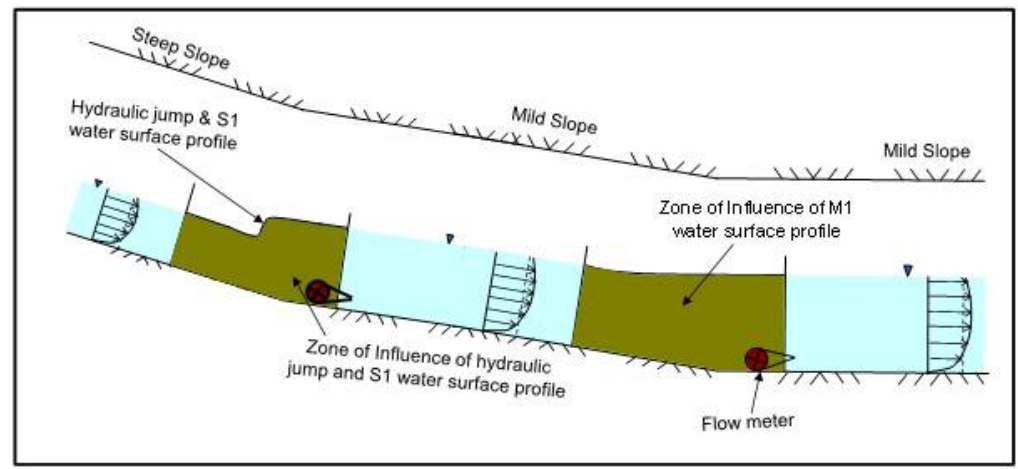

Figure 14.10 Surface profile when flow is $20 \mathrm{ft}^{3} / \mathrm{s}(566 \mathrm{~L} / \mathrm{s})$.

The above example illustrates how using Froude number plot, Manning's flow curves, and knowledge about water surface profile transition can help an engineer gain a good understanding of the local hydraulics of flow monitoring locations. This understanding can help the engineer to configure and orient the installation of $\mathrm{A} / \mathrm{V}$ flow monitors to minimize the effect of local hydraulics on collected data. The next section discusses in detail how a flow monitor should be oriented based upon information about water surface profile transition.

\section{Orientation of Flow Monitors}

As a general rule of thumb, a flow monitor should be installed in such a way as to avoid reading depth and velocity of transitions. For example, in an M-1 transition, the monitor should be installed in the downstream conduit with the 
velocity sensor pointing downstream as shown on Figure 14.10. This is because the M-1 transition happens in the upstream conduit. Installing the monitor in the upstream conduit and pointing the velocity sensor upstream will cause the depth sensor to read the M-1 transition depth and the velocity sensor to read the faster velocity of the upstream flow. On the contrary, if the monitor is installed in the downstream conduit with the velocity sensor pointing downstream, it will read the more stable downstream subcritical normal depth and velocity. Similarly, in a hydraulic jump and S-1 transition, the monitor should also be installed in the downstream conduit with the velocity sensor pointing downstream as shown on Figure 14.10. This is because the hydraulic jump will always happen in the upstream conduit. Installing the flow monitor in the upstream conduit will expose the monitor to reading depth and velocity of the hydraulic jump and S-1 transition. On the other hand, because the jump has already occurred upstream, if the monitor is installed in the downstream conduit with the velocity sensor pointing downstream, the monitor will only be reading the downstream subcritical flow depth and velocity.

The flow regime (subcritical, critical or supercritical) of the upstream and downstream conduits, the relative positions of their normal depth $\left(y_{n}\right)$ and critical depth $\left(y_{c}\right)$ values, and the slopes of the conduits $\left(S_{o}\right)$ help to determine how to orient a flow monitor in a manhole through which a flow monitor is installed. The following subsections and Table 14.2 (overleaf) outline a general guideline for installing flow monitors in different types of flow regime and profile transitions.

\section{Subcritical Flow to Subcritical Flow}

If the elevation of upstream $y_{n}$ exceeds the elevation of downstream $y_{n}$, and downstream $S_{o}$ is not less than upstream $S_{o}$, then the transition would be M-2 then to M-1. In this case, install the flow monitor in the upstream conduit with the velocity sensor pointing upstream. This will prevent the flow monitor from reading depth and velocity of the transition. If downstream $S_{o}$ is less than upstream $S_{o}$, then the transition would only be M-1. In that case, install the flow monitor in the downstream conduit with the velocity sensor pointing downstream for reasons as described above.

If the elevation of upstream $y_{n}$ is less than the elevation of downstream $y_{n}$, and downstream $S_{o}$ exceeds upstream $S_{o}$, then there will only be an M-1 to an M-2 transition. In this case, install the flow monitor in the downstream conduit with the velocity sensor pointing downstream. This will prevent the monitor from being affected by the M-1 transition upstream. The orientation of the monitor would be the same as above for downstream $S_{o}$ being not greater than upstream $S_{o}$ as their profile transitions are all M-1. 
Table 14.2 Flow monitor placement under various conditions.

\begin{tabular}{|c|c|c|c|}
\hline $\begin{array}{l}\text { Normal depth of conduits } \\
\qquad\left(y_{n}\right)\end{array}$ & Slopes of conduits $\left(S_{o}\right)$ & $\begin{array}{l}\text { Profile } \\
\text { Transition }\end{array}$ & Sensor Placement \\
\hline \multicolumn{4}{|c|}{$\begin{array}{l}\text { When upstream and downstream conduits are in subcritical flow (upstream conduit } \\
\mathrm{Fr}<1 \text {, downstream conduit } \mathrm{Fr}<1 \text { ). }\end{array}$} \\
\hline \multirow[t]{2}{*}{ Upstr. $y_{n}>$ Downstr. $y_{n}$} & Downstr. $S_{o}>$ Upstr. $S_{o}$ & $\mathrm{M} 2 \rightarrow \mathrm{M} 1$ & $\begin{array}{l}\text { Upstream conduit with velocity } \\
\text { sensor pointing upstream. }\end{array}$ \\
\hline & Downstr. $S_{o}<$ Upstr. $S_{o}$ & M1 & $\begin{array}{l}\text { Downstream conduit with } \\
\text { velocity sensor pointing } \\
\text { downstream. }\end{array}$ \\
\hline \multirow[t]{2}{*}{ Upstr. $y_{n}<$ Downstr. $y_{n}$} & Downstr. $S_{o}>$ Upstr. $S_{o}$ & $\mathrm{M} 1 \rightarrow \mathrm{M} 2$ & Downstream conduit with \\
\hline & Downstr. $S_{o}<$ Upstr. $S_{o}$ & M1 & $\begin{array}{l}\text { velocity sensor pointing } \\
\text { downstream. }\end{array}$ \\
\hline \multirow[t]{4}{*}{ Upstr. $y_{n}=$ Downstr. $y_{n}$} & Downstr. $S_{o}>$ Upstr. $S_{o}$ & M2 & $\begin{array}{l}\text { Upstream conduit with velocity } \\
\text { sensor pointing upstream. }\end{array}$ \\
\hline & Downstr. $S_{o}<$ Upstr. $S_{o}$ & M1 & Downstream conduit with \\
\hline & & & $\begin{array}{l}\text { velocity sensor pointing } \\
\text { downstream. }\end{array}$ \\
\hline & Downstr. $S_{o}=$ Upstr. $S_{o}$ & No transition & $\begin{array}{l}\text { Upstream conduit with velocity } \\
\text { sensor pointing upstream. }\end{array}$ \\
\hline \multicolumn{4}{|c|}{$\begin{array}{l}\text { When upstream conduit is in subcritical flow and downstream conduit is in super- } \\
\text { critical flow (upstream conduit } \mathrm{Fr}<1 \text {, downstream } \mathrm{Fr}>1 \text { ) }\end{array}$} \\
\hline Upstr. $y_{n} \geq$ Downstr. $y_{n}$ & Downstr. $S_{o}>$ Upstr. $S_{o}$ & $\mathrm{M} 2 \rightarrow \mathrm{S} 2$ & $\begin{array}{l}\text { Upstream conduit with velocity } \\
\text { sensor pointing upstream. }\end{array}$ \\
\hline Upstr. $y_{n}<$ Downstr. $y_{n}$ & & $\mathrm{M} 1 \rightarrow \mathrm{S} 3$ & $\begin{array}{l}\text { Downstream conduit with } \\
\text { velocity sensor pointing } \\
\text { downstream. }\end{array}$ \\
\hline \multicolumn{4}{|c|}{$\begin{array}{l}\text { When upstream conduit is in supercritical flow and downstream conduit in subcriti- } \\
\text { cal flow (upstream conduit } \mathrm{Fr}>1 \text {, downstream conduit } \mathrm{Fr}<1 \text { ) }\end{array}$} \\
\hline Upstr. $y_{n}>$ Downstr. $y_{n}$ & Upstr. $S_{o}>$ Downstr. $S_{o}$ & $\mathrm{~S} 2 \rightarrow \mathrm{M} 1$ & $\begin{array}{l}\text { Upstream conduit with velocity } \\
\text { sensor pointing upstream. }\end{array}$ \\
\hline Upstr. $y_{n}<$ Downstr. $y_{n}$ & & $\begin{array}{l}\text { Hydraulic } \\
\text { jump } \rightarrow \text { S1 }\end{array}$ & $\begin{array}{l}\text { Downstream conduit with } \\
\text { velocity sensor pointing } \\
\text { downstream. }\end{array}$ \\
\hline Upstr. $y_{n}=$ Downstr. $y_{n}$ & & $\begin{array}{l}\text { Short region } \\
\text { of instability }\end{array}$ & $\begin{array}{l}\text { Upstream conduit with velocity } \\
\text { sensor pointing upstream. }\end{array}$ \\
\hline $\begin{array}{l}\text { From control structure } \\
\text { into subcritical flow }\end{array}$ & Mild downstr. slope & $\begin{array}{c}\mathrm{M} 3 \rightarrow \\
\text { hydraulic } \\
\text { jump } \rightarrow \mathrm{S} 1\end{array}$ & $\begin{array}{l}\text { Downstream of hydraulic jump } \\
\text { and S1 with velocity sensor } \\
\text { pointing downstream. }\end{array}$ \\
\hline \multicolumn{4}{|c|}{$\begin{array}{l}\text { When both upstream and downstream conduits are in supercritical flow (upstream } \\
\text { conduit } \mathrm{Fr}>1 \text {, downstream conduit } \mathrm{Fr}>1 \text { ) }\end{array}$} \\
\hline Upstr. $y_{n} \geq$ Downstr. $y_{n}$ & All combination of upstr. & $\mathrm{S} 2$ & Upstream conduit with velocity \\
\hline \multicolumn{4}{|c|}{ Other slope conditions } \\
\hline$y_{n}=y_{c}$ & Critical Slope & $\mathrm{C} 1$ and $\mathrm{C} 3$ & $\begin{array}{l}\text { Downstream of the transition } \\
\text { with velocity sensor pointing } \\
\text { downstream. }\end{array}$ \\
\hline$y_{n}=\infty$ & Horizontal slope & $\mathrm{H} 2$ and $\mathrm{H} 3$ & Upstream of the transition with \\
\hline$y_{n}=$ imaginary & Adverse slope & $\mathrm{A} 2$ and $\mathrm{A} 3$ & $\begin{array}{l}\text { the velocity sensor pointing } \\
\text { upstream. }\end{array}$ \\
\hline
\end{tabular}

If the elevation of upstream $y_{n}$ is the same as the elevation of the downstream $y_{n}$, and downstream $S_{o}$ is greater than the upstream $S_{o}$, then there will be an M-2 transition only and the flow monitor should be installed in the upstream conduit with the velocity sensor pointing upstream. If the downstream $S_{o}$ is less 
than the upstream $S_{o}$, then there will be an M-1 transition only and the flow monitor should be installed in the downstream conduit with the velocity sensor pointing downstream.

If the upstream $S_{o}$ and downstream $S_{o}$ are the same, then the determining factor for the orientation is not from profile transition (because there is none) but from turbulence that might be created by boundary layer separation as flow travels along the edge and leaves the velocity sensor. This also happens when upstream $y_{n}$ elevation is not equal to downstream $y_{n}$ elevation and upstream $S_{o}$ is not equal to downstream $S_{o}$. But in these cases, the effects of profile transition on accuracy of collected data are much greater than boundary layer separation and thus they are the determining factors.

When profile transition is not a factor, then the orientation of the flow monitor is determined by how effect of boundary layer separation between flow and velocity sensor can be minimized on velocity data. As the tip of a velocity sensor is usually conic, pointing it upstream prevents the velocity sensor from being affected by turbulence that would be created by the sensor itself if it were pointed downstream and flow hit the flat square back part of the velocity sensor first and created turbulence before flow went over the tip of the velocity sensor and was read. Thus, in this case, the preferred installation orientation is to install the monitor in the upstream conduit with the velocity sensor pointing upstream.

\section{Subcritical Flow to Supercritical Flow (Downstream $\mathrm{S}_{\mathrm{o}}>$ Upstream $\mathrm{S}_{\mathrm{o}}$ )}

If the elevation of upstream $y_{n}$ is not less than the elevation of downstream $y_{n}$, the profile transition would be from M-2 then to S-2. In this case, install the flow monitor in the upstream conduit with the velocity sensor pointing upstream. This is because flow changes from subcritical to critical then to supercritical at the junction where the two conduits join. Installing the flow monitor as described would prevent the flow monitor from reading the depth and velocity of the transitions.

If the elevation of upstream $y_{n}$ is less than the elevation of downstream $y_{n}$, then the profile transition would be an M-1 and then an S-3. In this case, install the flow monitor in the downstream conduit with the velocity sensor pointing downstream. As all of the transitions happen upstream, this will prevent the flow monitor from reading the depth and velocity of the transitions. Even though flow is subcritical upstream and looks to be more stable, because the M-1 transition can grow upstream depending on downstream depth, installing the flow monitor upstream can cause the depth sensor to read M-1 depth while the velocity sensor reads the velocity of upstream normal depth or the velocity of somewhere in between normal and M-1 depth, depending on how far the M-1 transition has grown upstream. This can cause the data collected by the 
depth and velocity sensors to be data from different parts of the flow (i.e. causing the sensors to be spatially desynchronized).

Supercritical to Subcritical (Upstream $\mathrm{S}_{\mathrm{o}}>$ Downstream $\mathrm{S}_{\mathrm{o}}$ )

If the upstream elevation of $y_{n}$ is greater than the downstream elevation of $y_{n}$, then the flow will go through an S-2 and then an M-1 transition. In this case, install the flow monitor in the upstream conduit with the velocity sensor pointing upstream. This is because the transitions happen in the downstream conduit and the supercritical nature of the flow in the upstream conduit prevents the transition from affecting the readings of the flow monitor.

If the upstream elevation of $y_{n}$ is less than the downstream elevation of $y_{n}$, then the flow will go through a hydraulic jump and an S-1 transition. In this case, install the flow monitor in the downstream conduit with the velocity sensor pointing downstream where flow returns to subcritical so that the depth and velocity sensors measure the depth and velocity of the downstream subcritical flow rather than the depth and velocity of the upstream hydraulic jump and S-1 transition.

If the upstream elevation of $y_{n}$ is equal to the downstream elevation of $y_{n}$, then the flow will go through a short region of instability in the downstream conduit. In this case, install the flow monitor in the upstream conduit with the velocity sensor pointing upstream to avoid the flow monitor from reading the depth and velocity of the downstream instability.

When the supercritical flow is controlled by an upstream hydraulic structure (e.g. sluice gate) and flows into a subcritical conduit, then there will be an M-3 transition followed by a hydraulic jump and an S-1 transition. In this case, install the monitor in the downstream conduit, downstream of the hydraulic jump and S-1 transition, with the velocity sensor pointing downstream so that the velocity sensor reads the downstream subcritical velocity rather than the velocity of the turbulence in the upstream M-3-hydraulic jump-S-1 transition.

The M-3 transition cannot happen at a steep slope-mild slope junction as there is a mathematical singularity right at the joint of the steep (supercritical) and mild (subcritical) slopes, since a shallow water wave cannot travel upstream in a supercritical flow regime to form a transition that shapes like an M-1 curve between the steep and mild slope conduits. For a steep slope-mild slope transition, flow always goes through a hydraulic jump in the upstream steep slope and then goes through an S-1 transition to seek normal depth in the downstream mild slope.

\section{Supercritical to Supercritical Flow}

If the elevation of upstream $y_{n}$ is not less than the elevation of downstream $y_{n}$ for all combinations of upstream $S_{o}$ and downstream $S_{o}$, the flow will go 
through an S-2 transition. In this case, the flow monitor should be installed in the upstream conduit with the velocity sensor pointing upstream as the S-2 transition will happen in the downstream conduit.

If the elevation of upstream $y_{n}$ is less than the elevation of downstream $y_{n}$ for all combinations of upstream $S_{o}$ and downstream $S_{o}$, the flow will go through an S-3 transition. In this case, if the downstream $S_{o}$ is greater than the upstream $S_{o}$, install the flow monitor in the upstream conduit with the velocity sensor pointing upstream because the transition will happen in the downstream conduit.

\section{Other Conduit Slope Conditions}

One should always avoid installing flow monitors in critical, zero (horizontal) or adverse slope conduits. Although a flow monitor can usually collect data at these locations, it is often extremely difficult to verify the quality of the collected data afterwards. This is because for a critical slope conduit, the flow is unstable and any irregularity at the bottom of the conduit can potentially trigger a hydraulic jump in the proximity of the irregularity.

For zero and adverse conduit slopes, the energy head difference between the upstream and downstream boundary conditions replaces gravity and becomes a dominant force that controls the flow. Manning's equation does not apply at these configurations and other equations such as the Bernoulli equation might be needed to analyze the flow in these conduits.

As the range of energy difference between upstream and downstream boundary conditions in a sewer system is highly variable, it becomes very difficult, if not impossible, to verify the quality of the collected flow monitoring data from these locations. However, if it is necessary to install a flow monitor at these kinds of locations, the following describes how the monitor should be installed.

\section{$C-1$ and $C-3$}

Install the monitor in the downstream conduit with the velocity sensor pointing downstream so that the velocity sensor will not be reading velocity of flow under the $\mathrm{C}-2$ or $\mathrm{C}-3$ transition.

\section{$H-2$ and $H-3$}

Install the monitor upstream of the location of critical flow and point the velocity sensor upstream away from the location of critical flow.

\section{$A-2$ and $A-3$}

Install the monitor upstream of the location of critical flow and point the velocity sensor upstream away from the location of critical flow. 
One should always pay attention to the effect of downstream controls on depth of flow in the downstream conduit of a flow monitoring location. All of the above suggestions assume that both the upstream and downstream conduits will reach normal depths at some point along their lengths. If there are controls that control the water surface elevation of flow in the conduits, then the elevations of those depths, rather than $y_{n}$, should be used to determine how water surface profile changes as flow moves from one conduit to another.

When in doubt, always draw the slopes of conduits, the elevations of $y_{n}$ and $y_{c}$ (or $y$ if there are controls), and all the water surface profile transitions between the conduits. Then the orientation of the flow monitor should be determined such that its reading will not be affected by profile transitions and controls. It should be noted that to determine the effects of controls on water surface profile and ultimately flow monitoring data, it may be necessary to draw the water surface profiles of more than 1 conduit upstream and downstream of a flow monitoring location. In this case, the number of conduits needed would be determined on a case by case basis depending on local hydraulics.

\subsubsection{Validation of Flow Monitoring Data}

After flow monitors are installed and depth, velocity and flow time series are generated, the time series should be validated before they are analyzed. Depending on the technology utilized, velocity sensors usually either record mean velocity, $V_{\text {mean }}$, or maximum velocity, maximum $V(y)$, of flow. If maximum $V(y)$ is recorded, the recorded data need to be reduced by a factor such that a mean velocity time series can be generated and a flow time series can be calculated by Equation 14.3. This factor will be referred as average to peak ratio (APR) hereinafter. The relationship between maximum $V(y), V_{\text {mean }}$, and $A P R$ can be illustrated by the following two equations.

$$
V_{\text {mean }}=\frac{\sum_{n=1}^{j} V\left(y_{n}\right)}{j}
$$

where:

$$
\begin{aligned}
V\left(y_{\mathrm{n}}\right)= & \text { velocity measurements made at depth } y_{n} \text { of flow } \\
& \text { during field calibration of velocity sensor, } \\
j= & \text { total number of velocity measurements made at } \\
& \text { different depths of flow during field calibration of ve- } \\
& \text { locity sensor, and }
\end{aligned}
$$




$$
A P R=\frac{V_{\text {mean }}}{\max V(y)}
$$

where:

$$
\begin{aligned}
A P R & =\text { average to peak ratio, and } \\
\max V(y) & =\text { maximum } V(y) .
\end{aligned}
$$

The APR of a velocity time series should be calculated and provided by the flow monitoring contractor to the client during field calibration of the sensor.

The engineer analyzing the flow monitoring data should be clear whether the delivered velocity time series is $V_{\text {mean }}$ or $\max V(y)$, and what the calculated APR is accordingly. If $\max V(y)$ is delivered, then a mean velocity time series should be generated by using Equation 14.7 above. If $V_{\text {mean }}$ is delivered, then the engineer should further inquire whether the delivered $V_{\text {mean }}$ is post processed or recorded by the velocity sensor. Some newer velocity sensors take multiple measurements along the depth of flow, already have Equation 14.6 programmed into the instrument, and report $V_{\text {mean }}$ rather than $\max V(y)$. If this is the case, the velocity time series does not require further processing. But if $\max V(y)$ is what the sensor records and the conversion calculation from $\max V(y)$ to $V_{\text {mean }}$ is completed either by the sensor internally via Equation 14.7 with a user provided APR, or by the flow monitoring contractors externally before the data was submitted to their clients, then the engineer analyzing the data should request documentation from the contractor on what APR values are used to generate $V_{\text {mean }}$ from $\max V(y)$.

As for the validation of depth time series, it depends on the technology and configuration of the ultrasonic and pressure transducers used. The engineer analyzing the flow monitoring data should be aware of what technology is used by the flow monitor equipment to measure depth and how the values in the delivered depth time series were generated.

After both depth and mean velocity time series are validated, a calculated flow time series should be generated by multiplying the validated mean velocity time series by the corresponding cross-sectional area time series calculated from the validated depth time series. This calculated flow time series should be used to validate the final flow time series delivered by the flow monitoring contractor.

\subsubsection{Analysis of Flow Monitoring Data}

After depth, velocity and flow time series are validated, it is time to analyze the data. In addition to selecting flow monitoring locations, the five fundamental concepts discussed above can also be used to analyze flow monitoring data. The use of these concepts in analyzing flow monitoring data will be illustrated by the following two examples. 
To use the fundamental concepts, plot the depth and mean velocity time series onto the mean velocity profile plot, depth and flow time series onto the Manning's flow plot, and mean velocity time series and celerity time series calculated from depth time series onto the Froude number plot of the conduit in which the flow monitor is installed. Figures 14.11 to 14.13 show a set of examples of these plots with flow monitoring data.

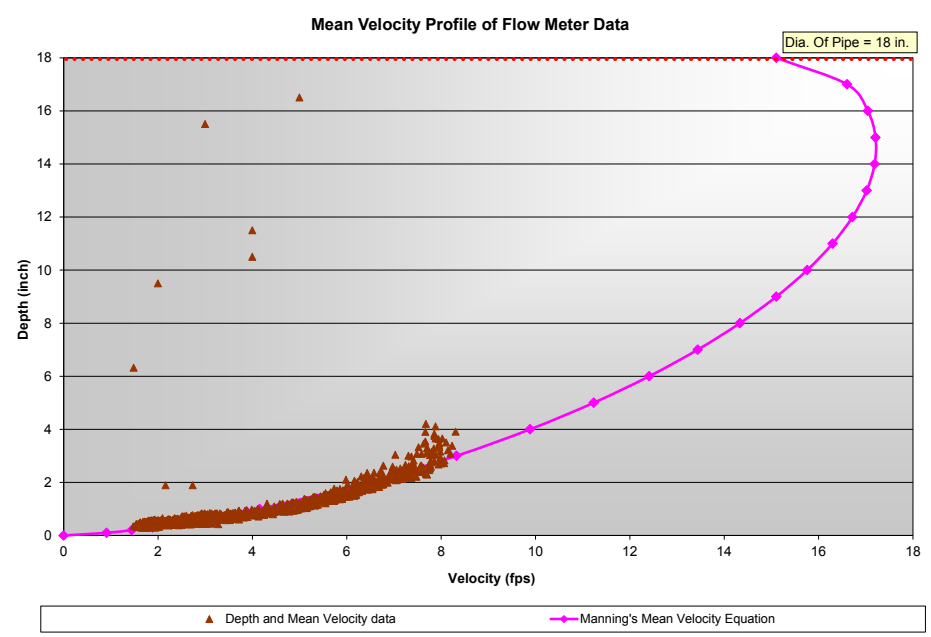

Figure 14.11 Flow monitoring data plotted onto a mean velocity profile plot.

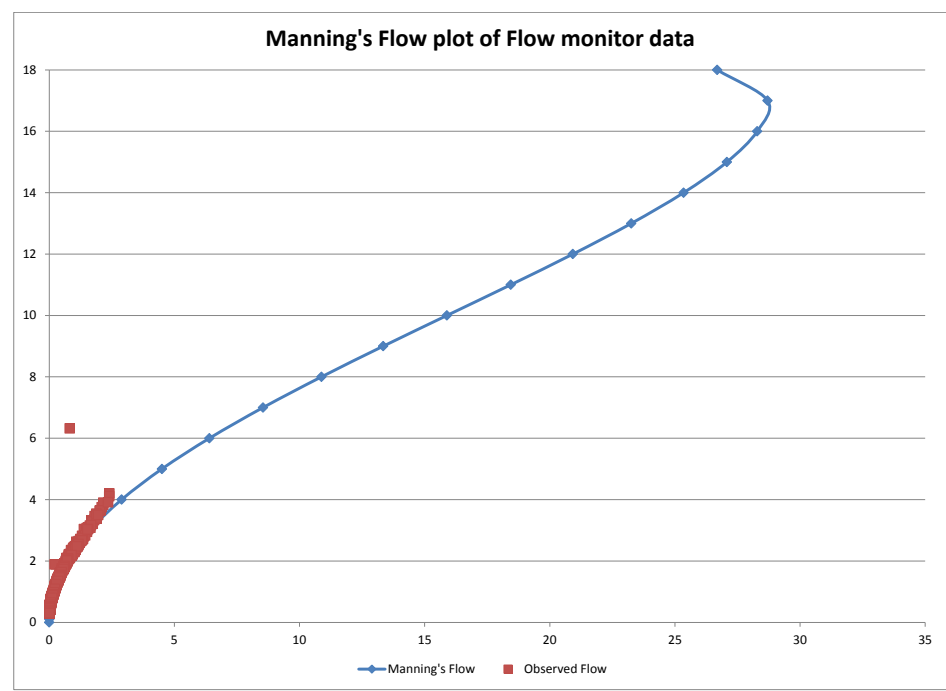

Figure 14.12 Flow monitoring data plotted onto a Manning's flow plot. 


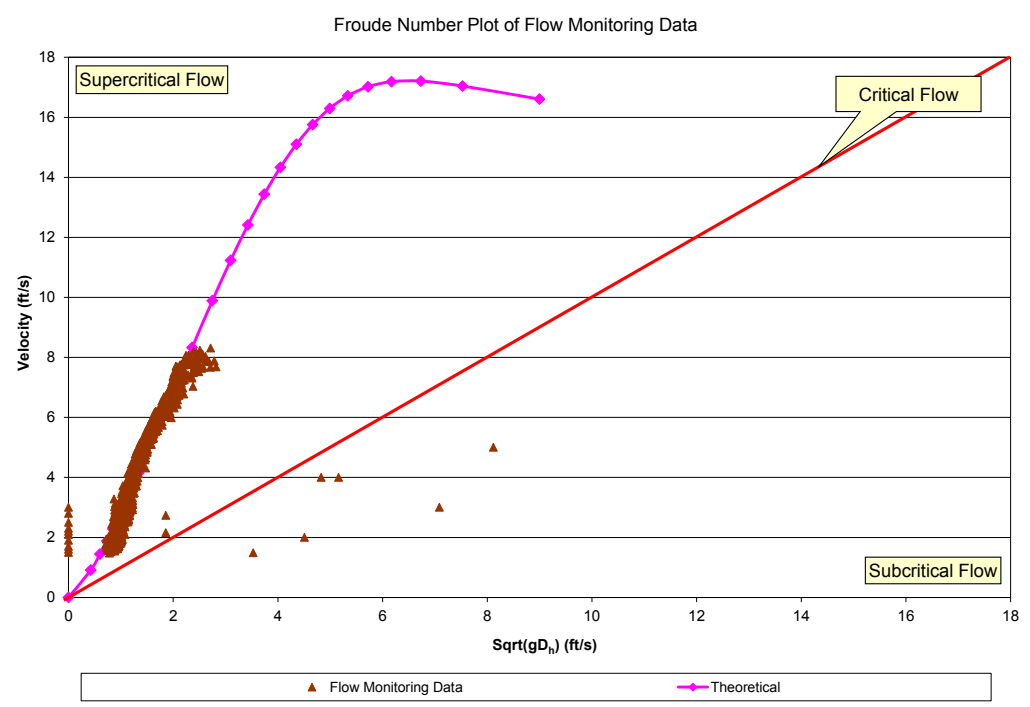

Figure 14.13 Flow monitoring data plotted onto a Froude number plot.

After the data are plotted, apply the five fundamental concepts in an integrated manner to analyze the three plots simultaneously and note the hydraulics registered by the data. Good flow monitoring data collected at an uncontrolled location without any hydraulic phenomena should agree well with the conduit's mean velocity profile curve, Manning's flow curve and Froude number curve as in the example shown on Figures 14.11 to 14.13.

If flow is controlled, or experiences hydraulic phenomena, or the flow monitoring equipment malfunctions, the flow monitoring data will deviate from the conduit's curves. In that case, apply the fifth fundamental concept and plot the depth and velocity time series onto the same graph against the same time axis as on Figure 14.7.

Then apply the five fundamental concepts together onto all four plots along with any other information about local hydraulics (e.g. locations of controls), and determine the effects of controls, what kind of hydraulic phenomena occurred, and whether the flow monitoring equipment indeed malfunctioned.

Finally, decide whether the data can be used and how they can be best used for their originally intended purposes (e.g. model calibration or design). An example of a set of flow monitoring data collected from a location that experiences a hydraulic jump is shown in Figures 14.14 to 14.16. 


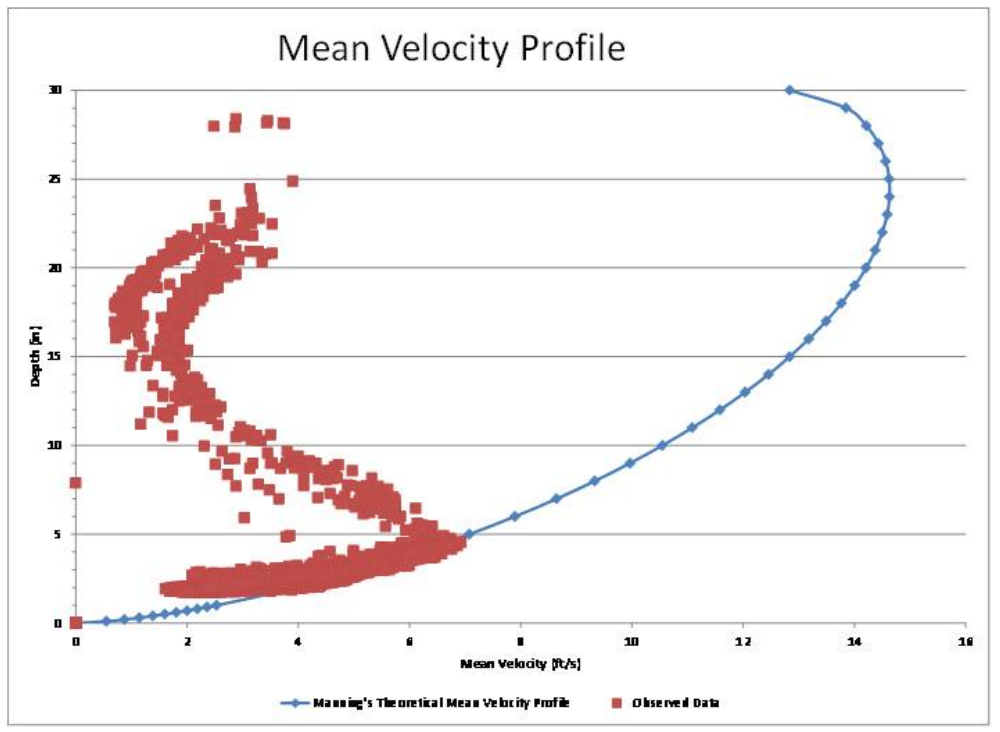

Figure 14.14 Mean velocity profile of flow monitoring data affected by hydraulic jump.

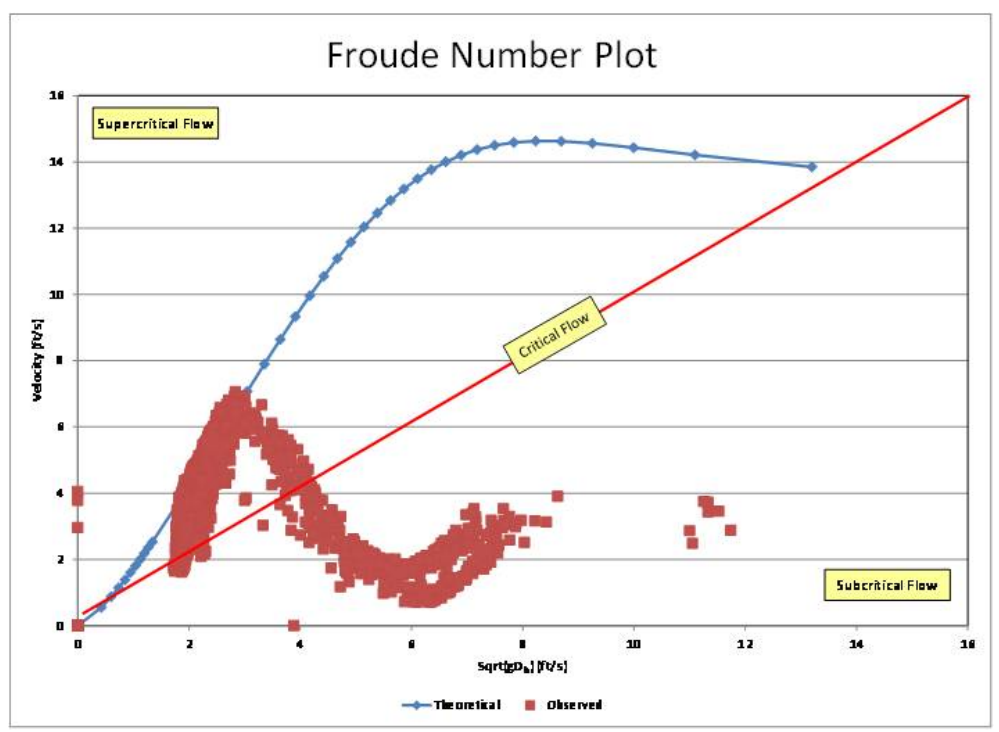

Figure 14.15 Froude number plot of flow monitoring data affected by hydraulic jump. 


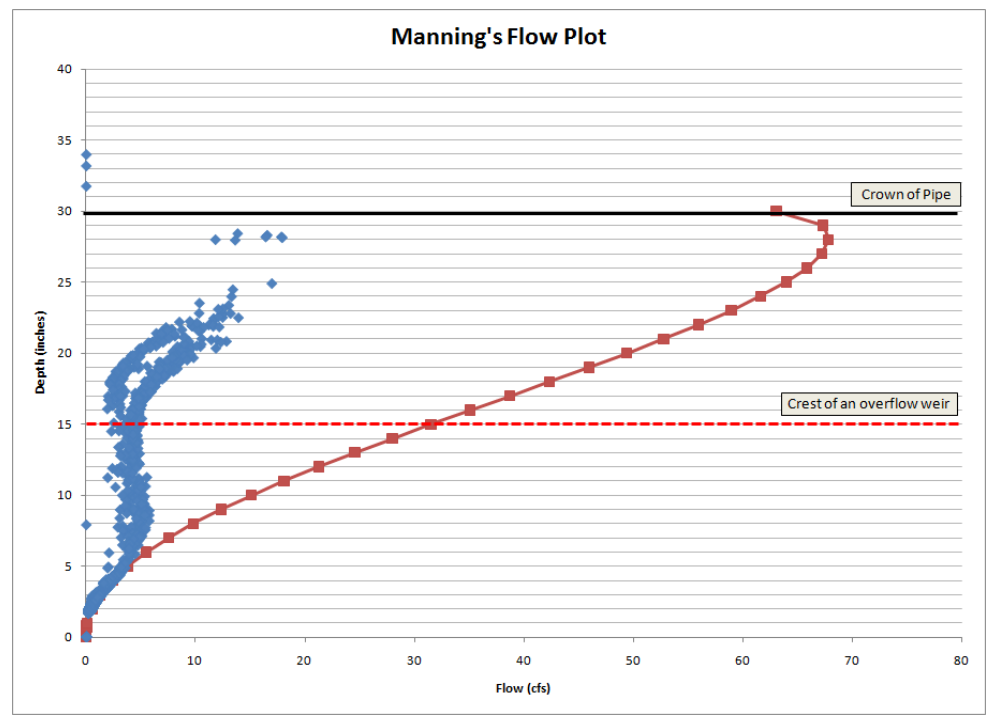

Figure 14.16 Manning's flow plot of flow monitoring data affected by hydraulic jump.

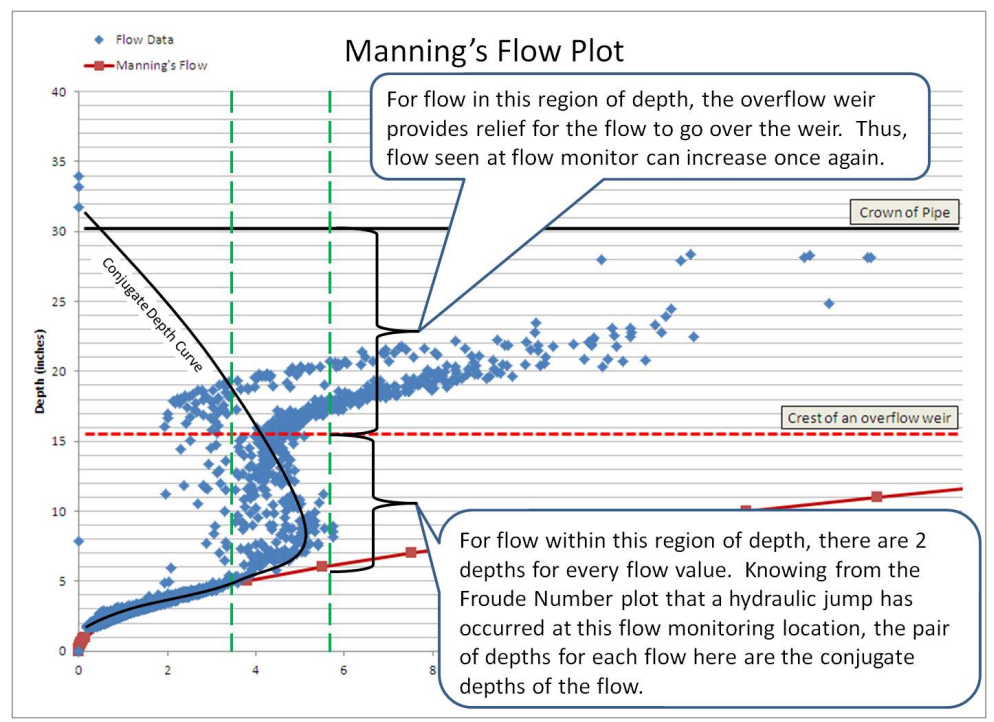

Figure 14.17 Conjugate depth of flow.

From the Froude number curve (diamonds line) shown on Figure 14.15 it is clear that flow in the conduit should be supercritical. However, the flow monitoring data (square dots) cross from the supercritical region to the subcritical region. This shows that the flow in the conduit experienced a hydraulic jump. 
Knowing that a hydraulic jump occurred at the flow monitoring location, the Manning's flow plot of the conduit, as shown on Figure 14.16, can be used to estimate the conjugate depths of the jump for different flows in the conduit. This is possible because the Manning's flow plot is a plot of depth versus flow. Figure 14.17 (above) zooms into the flow monitoring data of Figure 14.16.

Figure 14.17 shows a Manning's flow plot with flow monitoring data and a conjugate depth curve fitted onto the data. The conjugate depth curve can be used to determine the conjugate depths of flow in the conduit at different flows. Such information is very useful for design purposes, such as determining the elevation of a weir crest needed to contain the hydraulic jump. Additional information about the hydraulics of the flow monitoring location can also be plotted onto a Manning's flow plot to provide more information about the hydraulics experienced by the flow monitoring data. For the case of Figure 14.17, the height of a weir crest is shown on the Manning's flow plot. The indication of the height of the weir on the plot explains why depth and flow increases again when the depth of flow reaches 15.5 in. $(394 \mathrm{~mm})$. This is because when depth of flow reaches the height of a weir, the weir provides an alternative route for the flow to move.

If one looks at the flow monitoring data on Figure 14.17 closely, one can probably see that the flow monitoring data seem to be showing that there can be two conjugate depth curves in the data. Such observation is correct, as the cause of the hydraulic jump for this set of data is a flap gate pushing against the flow. When the flow is low, the force that the flow exerts on the flap gate is smaller and this causes the jump to occur sooner. As the amount of flow that pushes against the flap gate increases, the flap gate opens more and allows more flow to go through. This delays the happening of the hydraulic jump. The conjugate depth curve shown on Figure 14.17 is one for the higher flow as more flow data points fall onto that curve rather than the different earlier curve. However, the spread of the data suggests that the curvature of the conjugate depth curve changes constantly as flow increases and the gate opens more. Such information is very important in projects such as redesign of the flap gate.

Another example is shown by Figures 14.18 to 14.20 . This example illustrates what can happen to flow monitoring data if the water surface profile transitions of a flow monitoring location are not considered during the flow monitor location selection process and not all three plots are analysed together during flow monitoring data analysis. It should be emphasized that the fourth plot - temporal synchronization of depth and velocity time series - should be included in the analysis if the type of hydraulic phenomena that occurred or the causes of data anomalies cannot be identified from the first three plots. This is because the anomalies in the flow monitoring data might be due to the presence of controls or the malfunction of flow monitoring equipment. 


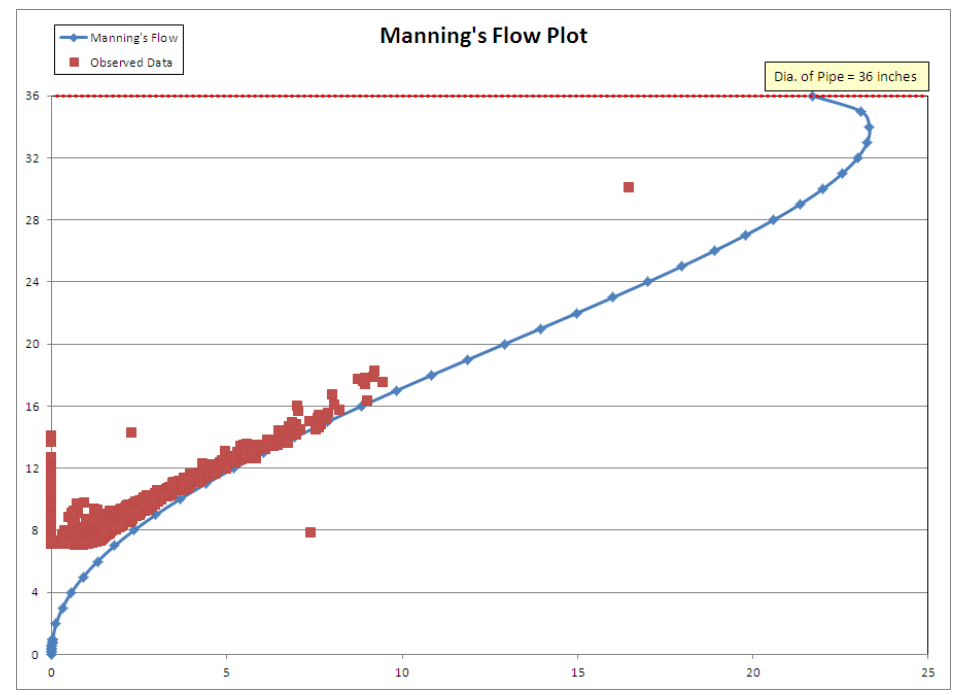

Figure 14.18 Manning's flow plot of a vertically shifted depth data.

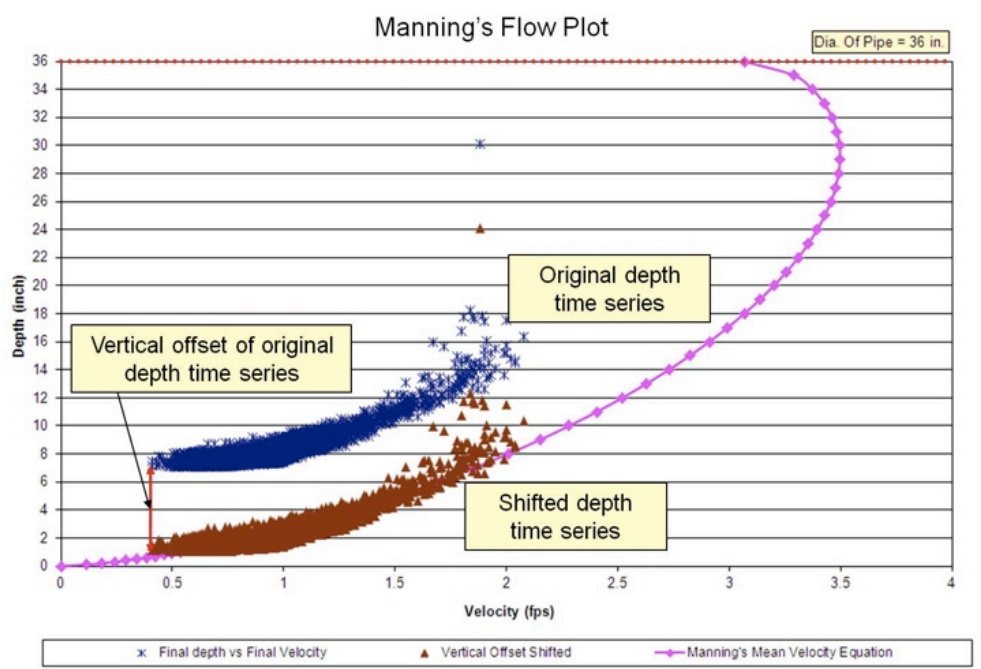

Figure 14.19 Mean velocity profile of vertically shifted depth data.

By looking at just the Manning's flow plot shown on Figure 14.19 (above), it seems that the flow monitoring data are fairly good. It seems like only the initial part of the data does not follow the Manning's flow curve of the conduit and the rest of the data follows the curve fairly well. Figure 14.20 and 14.21 
show the mean velocity profile and Froude number plots of the conduit with flow monitoring data.

After looking at the mean velocity profile plot of the flow monitoring data, we see that the depth time series (star scatter plot on Figure 14.20 and 14.21) was actually vertically shifted by 6 in. $(164 \mathrm{~mm})$. This shift can also be observed in the Froude number plot of the flow monitoring data as shown in Figure 14.21.

\section{Froude Number Plot}

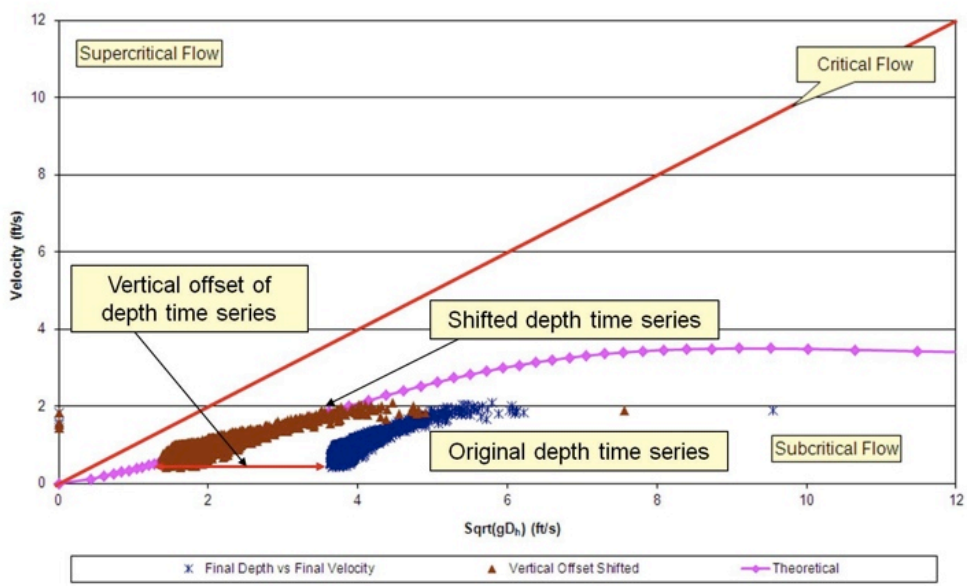

Figure 14.20 Froude number plot of vertically shifted data.

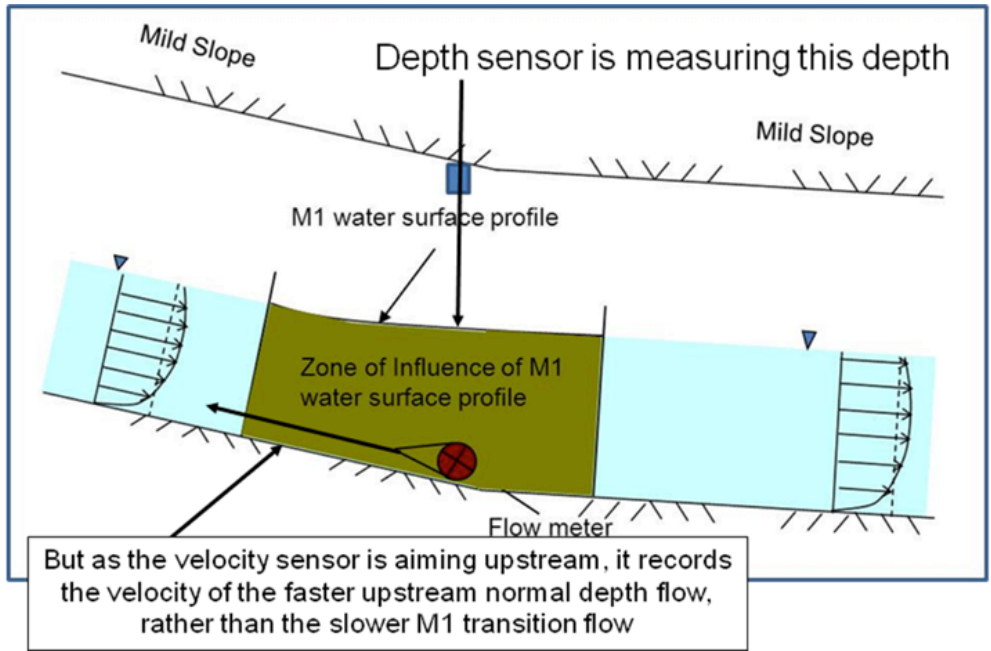

Figure 14.21 Configuration of the flow monitoring installation. 
Examination of the slope of the conduit in which the flow monitor was installed, the slope of the immediate downstream conduit and the orientation of the flow monitor, reveals that the flow monitoring location experienced an M-1 water surface profile transition and that the velocity sensor was aiming upstream rather than downstream. Figure 14.21 (above) shows a diagram of the configuration of the flow monitor installation in relation to the surface profile transition.

As shown on Figure 14.21, as the flow monitor was installed in the upstream conduit rather than the downstream conduit, the depth sensor was measuring the depth of the M-1 transition. Furthermore, as the velocity sensor was pointing upstream rather than downstream, the velocity sensor was recording the faster upstream normal depth velocity rather than velocity of the flow in the M-1 transition. Thus, the depth data and the velocity data were spatially desynchronized. In order to resynchronize the two time series, the depth data will need to be revised from M-1 transition to normal depth since the velocity sensor was recording the velocity of the upstream normal depth flow. Figures 14.19 and 14.20 above also show the adjusted depth time series (triangles scatter plot) plotted onto the mean velocity profile and Froude number plots. Figure 14.22 shows what Figure 14.18 looks like with adjusted depth data and Figure 14.23 shows the difference between the original flow time series and the flow time series created by the adjusted depth time series.

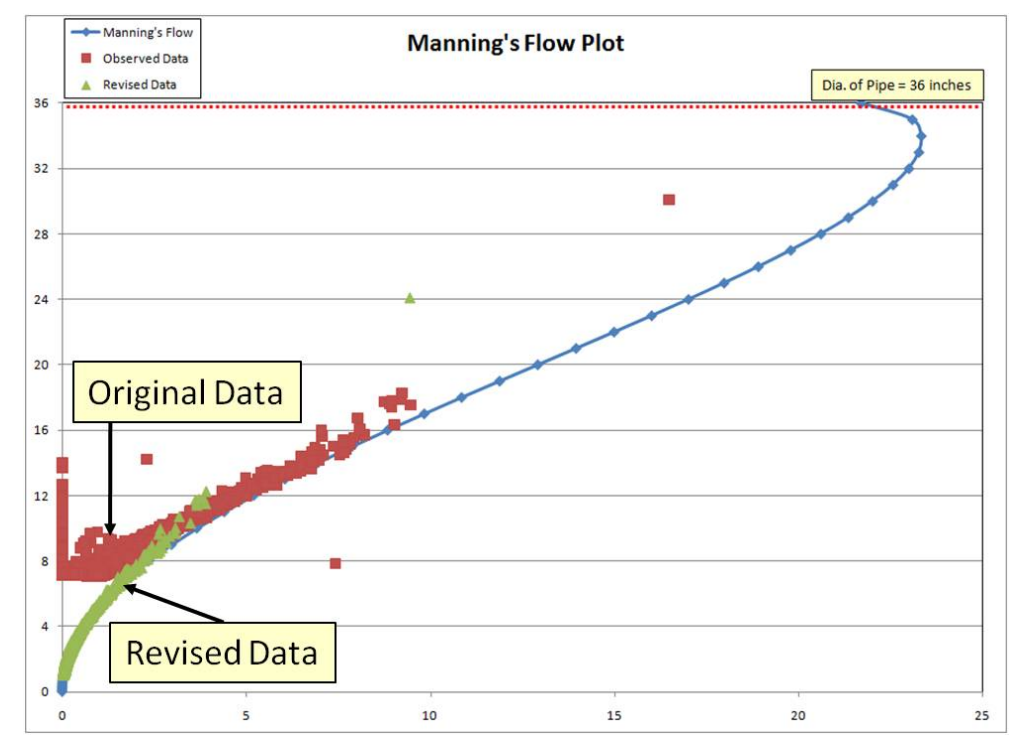

Figure 14.22 M-1 transition flow monitor installation configuration. 


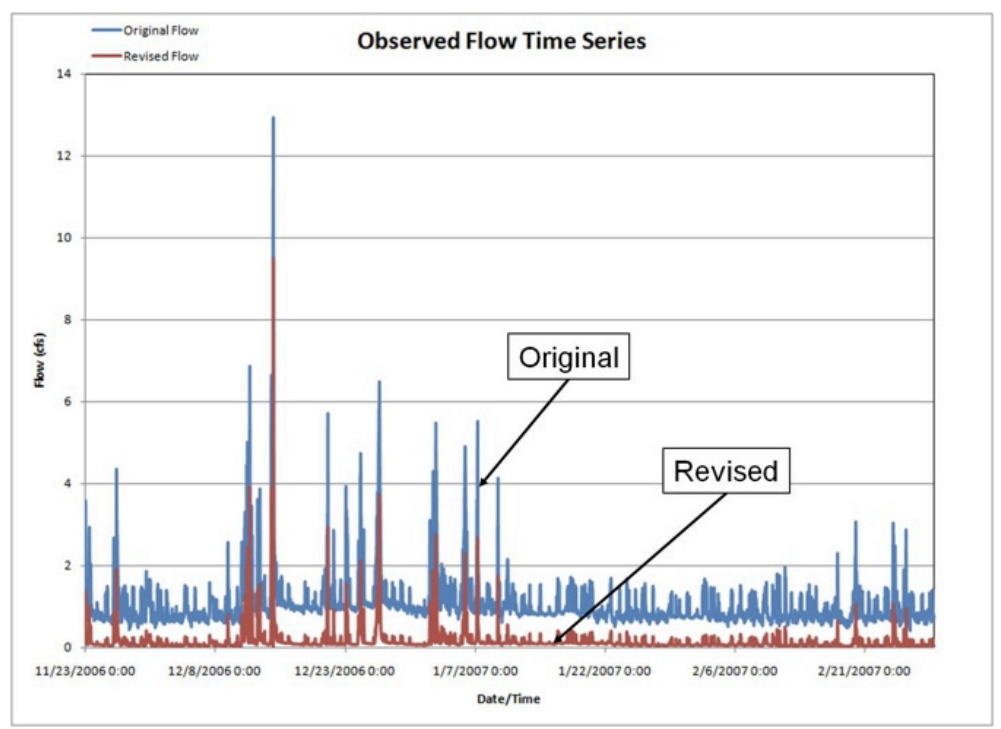

Figure 14.23 Difference between original and revised data.

From Figure 14.23, one can see that if the original data were not appropriately analysed, and the data were used for model calibration or the sizing of hydraulic structures, the calibrated model would overestimate the flow and the hydraulic structures would be oversized. In fact, besides mechanical malfunctions such as velocity sensor drifting (as discussed in section 14.1.5), the spatial desynchronization of depth and velocity data is one of the more common reasons why flow data collected from monitors installed in sequence geographically do not agree.

\subsection{Conclusions}

The five fundamental concepts applied in context provide a set of valuable tools for selecting flow monitoring locations, validating and analyzing flow monitoring data. By using the five fundamental concepts in selecting flow monitoring locations and orienting flow monitoring sensors, an engineer can gain a good understanding of local hydraulics (e.g. location of a hydraulic jump) and select locations and orient sensors based upon the information of the hydraulics and the intended use of the collected data. The increased understanding would also help the engineer in validating flow monitoring data as they would then know what to expect from the flow monitoring data, and be able to quickly identify and correct any problems during the data collection process. 
When validated flow monitoring data are analyzed systematically using the five fundamental concepts with all four of the associated plots and five sets of transition curves, the results of the analysis can provide much valuable information about the quality of the data and further information about the local hydraulics (e.g. conjugate depths of a hydraulic jump) of the flow monitoring location. They provide information to engineers about whether anomalies in monitoring data are caused by effects of controls, hydraulic phenomena or other factors such as the mechanical malfunctioning of monitoring equipment.

Even when an initial visual evaluation of flow time series does not reveal any issues with a set of flow monitoring data, one should always analyze the data using the five fundamental principles with all four of the associated plots and the five sets of transition curves. This will ensure that the goodness of the quality of the flow time series generated from the flow monitoring data was based upon good underlying flow monitoring data.

If the quality of data is better understood, this also contributes to reducing potential errors in any subsequent calculations and model calibration that rely on the flow monitoring data as input. It also eases the hydrodynamic model calibration process in helping to decide whether discrepancies between model results and flow monitoring data are due to the quality of the calibration, properties of specific hydraulics at the monitoring location (e.g. the effect of controls such as weirs or hydrobreaks), hydraulic phenomena such as hydraulic jump and water surface profile transition, or the quality of the flow monitoring data.

\section{Acknowledgment}

Portions of this chapter are based upon material published earlier in Application of Mean Velocity Profile, Depth and Velocity Data Time Series, and Froude Number to Flow Monitoring Location Selection and Flow Monitoring Data Analysis, the copyright of which is held by the Water Environment Federation (WEF) Specialty conference 2008. Permission has been granted by WEF to use material from that paper in this chapter with the following acknowledgement: Reprinted with permission from Proceedings of Water Environment Federation Collection Systems Specialty Conference, May 18-21, 2008, Pittsburgh, Pennsylvania. Copyright (C) 2008 Water Environment Federation, Alexandria, Virginia.

\section{References}

Daugherty, R.L., Franzini, J.G. and Finnemore, E.J. 1985. Fluid Mechanics with Engineering Applications - 8th Edition. New York: McGraw-Hill, Inc. 
Pang, J. 2008. Application of Mean Velocity Profile, Depth and Velocity Data Time Series, and Froude Number to Flow Monitoring Location Selection and Flow Monitoring Data Analysis. Proceedings of Water Environment Federation Collection Systems Specialty Conference, Pittsburgh, Pennsylvania, USA. May 18-21, 2008.

White, F.M. 1994. Fluid Mechanics - Third Edition. New York: McGraw-Hill Book Co. 